\title{
Interactive Reading Model and College English Reading
}

\author{
$\mathrm{Fu} \mathrm{Bo}{ }^{1, a}$ \\ ${ }^{1}$ Jilin Agricultural University, College of Foreign Languages, Changchun,130118,China \\ aivy510@126.com,
}

Keywords: interactive reading model; collage English reading; reading strategies; reading proficiency; English reading teaching

\begin{abstract}
The present thesis attempts to find the solution to problems in college non-English majors' reading teaching and learning. Most students are eager to learn how to read effectively although their teachers can not meet such demand perfectly, which results from the lack of training and systematic planning in their teaching practice. The solution proposed in this paper is the application of the interactive reading model in English reading class, which aims at developing students' reading skills and strategies as well as elevating their language proficiency by some principles based on the interactive reading model. The model is worthy adopted from both theoretical and practical points of view. This thesis begins with discussion on the difference among the chief reading models such as Gough's Bottom-up Model, Goodman's Top-down Model, Rumellhart's Interactive Model and Schema-theoretic Model in doing reading comprehension. And then it is about the definition of reading and the meaning of reading comprehension, and the nature of reading process, which demonstrates how interactive reading model reveals the essence of reading process. Based on this model, some reading strategies and skills for EFL reading such as building up and activating the reader's background knowledge and teaching methods such as the application of the interactive reading model in the word attacking are presented. And an exemplification based on the principles mentioned above is presented in order to compare with the commonly employed conventional reading teaching model in term of the achievement of students' reading comprehension abilities. The purpose of reading at college EFL reading course is to train students' reading ability and to improve students' language proficiency; meanwhile, teachers should try to make students involved in the reading activities. By combining such elements as the guidance of a proper theory, appropriate reading skills and strategies and immense reading practice, more and more successful and efficient readers will appear in the very near future.
\end{abstract}

\section{Introduction}

Reading is one of the main ways to get information for English learners. Reading ability largely determines the amount of the information one gets. One of the main problems that plague Chinese English-learners in their learning is the difficulty they encounter in improving their reading ability. EFL (English as a foreign language) reading is one of the main training courses in a foreign language learning classroom. That is one of the reasons why reading teaching and learning have attracted so much attention from the researchers who have done the research from the reading process study to reading strategies exploration. As an internationalized language, English undoubtedly has become a vitally important language and English learning has become indispensable task of one's life. It has started to play an increasingly important role in our social and economic life.

Reading is definitely the most important language skill to obtain information and get access to the foreign cultural knowledge. Most foreign language learners often regard reading as one of their most important goals to be able to read for information, for pleasure, for their career, and for academic achievements. And extensive exposure to linguistically comprehensible written texts can enhance the process of language learning. Good reading ability is beneficial to other abilities to some extent. So, reading is a skill which is highly valued by both students and teachers.

In China, researches on English reading can primarily be classified into the following areas: the 
researches on reading process, the researches on the choice of appropriate reading materials, the researches on the training of reading skills. Comparatively, little devotion can be found in improving reading from the aspect of learning and reading strategies. So, through the study concerning reading strategies and reading proficiency, this thesis seeks to throw some light on the improving English reading for non-English majors in China. The present thesis makes a very general introduction of the development of the reading models from top-down to bottom-up, and then to interactive. And the long-term goal of college English reading teaching is not only to make students master some effective reading strategies to cultivate their ability of reading in English and using the language, but also to cultivate their ability to think independently and critically.

\section{Reading strategies based on the interactive reading model}

The effective reading strategies play an important vital role in one's reading comprehension. Reading strategy is a part of language learning strategy, which can not be separated from the latter. Reading strategies indicate how readers conceive a task, what textual cues they attend to, how they make sense of what they read, and what they do when they do not understand. They range from simple fix-up strategies such as simply rereading difficult segments and guessing the meaning of an unknown word from context, to more comprehensive strategies such as summarizing and relating what is being read to the reader's background knowledge. So, if students have a good command of reading strategies, they must take advantage of efficient reading.

Not all meaning is clearly stated. Most authors expect a reader to "read between the lines" or to draw inferences, in order to get a clearer understanding of the ideas presented. The ability to predict what the writer is going to say next is both an aid to understanding and a sign of it. Prediction refers to making inferences from the content of a passage before reading, usually with the combination of personal knowledge and experience of the reader. In other words, the more accurate prediction provided by readers with the help of their background knowledge, the less information needed to be drawn in ensuring a successful comprehension, and the faster the reading process could be accomplished.

A fundamental require of the interactive reading model is to grasp the main idea of a writing, that's the basis for the reader and author to achieve common thoughts. Finding main ideas is one of the most important specific comprehension skills. This could be a literal skill if the idea is directly stated, or an inferential skill if it is not directly stated .The main idea is the essence of a piece of writing, or what the author is trying to get across to the reader. If a reader were to discard the main idea, the remaining sentences would be practically meaningless.

Therefore, the reader gets the implied main idea by "reading between the lines". Because it could be found anywhere in the paragraph, and could be stated or implied, a reader should have a plan to facilitate finding the main idea. This could be done by asking himself the following questions after he reads a paragraph or a passage.1. What is the topic of the paragraph? The topic of the paragraph is who or what is about. For example, the topic could be onions, the space shuttle, Abraham Lincoln, or drug abuse. A reader cannot determine the main point the author is trying to make until he knows what the author is talking to make until he know what the author is talking about. However, merely knowing what topic the author is discussing will not give you the main idea. After a reader determines the topic, or subject, of the paragraph, he should then discuss the next two questions about the topic. 2. What aspect of the topic is the author discussing? Most topics are broken down into small aspects. 3. What main idea does the author wants you to know about the topic in relation to the aspect being discussed? After a reader has determined the topic and the aspect of the topic been discussed, he can determine what idea the author wants him to know.

In the preceding sections, we have learned that after one comprehends what is stated, he needs to read "between the lines" to get a clear meaning by understanding the author's implied meanings. To be a truly successful reader, one must read beyond what is stated and implied so that he can analyze the material according to his purpose for reading. Critical reading is an active, creative skill that requires you to question, compare, and evaluate.

Critical-reading skills are necessary in order to determine the value of reading material, to detect 
faulty logic and information, to separate facts from opinions, then to determine whether a reader needs to accept or reject the information. If a reader never questioned what he read, he would accept every bit of information as fact and every author's opinions as his own, simply because a material is published does not make it relevant to his needs. If a reader never compared what he read, he would have no standard by which to judge and would not be able to select the best information for his needs. Comparison is essential, especially when he reads conflicting information and interpretations. If a reader never evaluated, he would never know whether what he read is valuable or whether it is worthless. In other words, he would not know whether the reading material was worth his valuable time.

Critical reading could be considered a form of critical thinking. One thinks critically each day in everything he does. It is the means by which he makes each decision, purchase any product, and decide what to say or do in any situation. Critical thinking also guides one in developing opinions of major and minor happenings in his life. For example, one uses critical thinking (and reading) when he decides which brand of jeans to buy. First, he questions the cost, shrinkage, durability, and appearance. Next, he compares the brand he is considering with other brands he has worn, heard about from friends, or seen advertised. Finally, he evaluates on the basis of his own needs, budget, and personal taste. Then, and only then, is he ready to make the purchase that is best suited for him. This same process can, and indeed should, be applied to everything he reads. At first the process of critical reasoning sounds long and tiresome. However, it actually saves a reader time by guiding him in selecting only the material relevant to his needs and personal taste. The process also increases his total comprehension because the analysis aids in understanding what the author actually intended.

What students do after reading can be just as important as what they do before and during the interactive reading process. Effective reading does not end with a reader's arrival at the last word of the text. On the contrary, to obtain a sense of closure, strategic readers engage in the three complementary follow-up behaviors of retelling, summarizing and evaluation. Retelling and summarizing require readers to enhance his comprehension of the target passage with all the information they gained from the bottom, that is, from the words, sentences, and paragraphs, even the whole passage. However, evaluation is when readers purposefully integrate information in the text with their background knowledge and then react to it. They all are basic follow-up reading strategies of interactive reading model. And together they enable readers to personalize the meaning of a selection.

On the surface, summarizing would appear to be an easily acquired strategy, but this is not the case in successful reading teaching class. It is a cognitively challenging response to text. Summarizing is closely related to and may be dependent on the strategy of paraphrasing, which is the rephrasing of the main idea of a paragraph or short passage. Summarization requires an understanding of what was read as well as the ability to put that understanding into one's own words after a thorough mingling the information conveyed with his own schemata. It also demands a certain amount of brevity. Readers must learn to reduce the text to its gist, condensing without omitting key ideas, maintaining the author's point of view, and sequencing the information in a logical way. The goal of summarization is to capture the essence of the text clearly and concisely. And it always follows the rules below: responding to different situation. From the bottom to the top and from the top to the bottom, retelling, summarizing and evaluation embody the interaction of the bottom-up reading processing.

\section{Summary}

The interactive reading model has attracted great attention from the researchers both abroad and home. The present research is carried out mainly to prove the effect of the interactive reading model in improving readers' reading proficiency. The interactive reading model is superior to the other reading models because it recognizes the interaction of the high-level and low-level reading processes simultaneously during doing reading comprehension. The obvious disparity of test performances between the experimental class and the control class has provided the significant 
proof to clarify the effect of the interactive reading model. When it comes to the pedagogical field, the interactive intensive reading class takes the tasks to improve both students' high-level and low-level processing abilities. In other words, in the interactive intensive reading class, students must be familiar with the top-down reading skills such as predicting, previewing, guessing etc. as well as bottom-up reading skills such as word recognition etc.

Though a variety of interactive reading strategies and skills have been introduced by researchers, it is the English teachers who take the responsibility to introduce and pass these skills and strategies to students and even the teachers themselves are researchers to explore more efficient reading skills and strategies on the base of their specific teaching environment. The ways for teachers to carry out the tasks are various, but intensive reading class is the most direct and main field. In the application of interactive reading strategies, over-reliance on text or on context or on background knowledge may cause the negative results that certain students may overcompensate for a lack of relevant schemata by reading in a slow text-bound manner, and other students may overcompensate by guessing. So both teachers and students must hold a balance between the top-down and bottom-up reading skills. Interactive reading model suggests that background knowledge play a significant role while reading. And lots of strategies and skills to build up and activate students' background knowledge are introduced and adopted by the teachers in class. Teachers can act as the director to stimulate students to construct their own reading strategies through the process of information recognition and students are encouraged to enrich their own knowledge through reading materials, video, Internet, even life experience.

This study leaves a number of topics for the future research. What is worthy of investigation is the research in the students' learning styles and learning motivation into consideration. Teacher's knowledge background, teaching experience, understanding into and attitude toward interactive reading model and personal teaching style should be examined to determine if individual teacher's efforts would produce different results. By combining such elements as the guidance of proper theory, appropriate reading skills and strategies, and immense reading practice, rather successful and efficient reader will be omnipresent.

\section{References}

[1] Scrivener, J. Learning Teaching: a Guidebook for English Language Teachers [M]. Shanghai: shanghai Foreign Language Education Press.(2002)

[2] Silberstein, S. Techniques and Resources in Teaching Reading [M]. Shanghai: shanghai Foreign Language Education Press. (2002)

[3] Skeham, P. Individual Differences in Second Language Learning [M]. London: Edwin Arnold. 1989.

[4] Scorace, A. Second Language Learning Data Analysis [M]. Lawrence Erlbaum Associates Publishers. 1994.

[5] Stern, H.H. Fundamental Concepts of Language Teaching [M]. Oxford: Oxford University Press. 1983.

[6] Ungerer, F. \& H.J. Schmid. An Introduction to Cognitive Linguistics [M]. Beijing: Foreign Language Teaching and Research Press. 2001.

[7] Wilga, M. Interactive Language Teaching [M]. Cambridge: Cambridge University Press. 1997. 